\title{
Innovative and sustainable business models in the fashion industry: Entrepreneurial drivers, opportunities, and challenges
}

\author{
Bruna Villa Todeschini ${ }^{a, *}$, Marcelo Nogueira Cortimiglia ${ }^{a}$, Daniela \\ Callegaro-de-Menezes ${ }^{a}$, Antonio Ghezzi ${ }^{b}$
}

\author{
a Universidade Federal do Rio Grande do Sul, Porto Alegre, Brazil \\ b Politecnico di Milano, Milan, Italy
}

\begin{abstract}
New and existing companies are looking for ways to thrive in a competitive environment with innovative business models while respecting society and avoiding actions that harm the planet. Trends such as circular economy, fair trade, lowsumerism, and sharing economy are some of the many emerging entrepreneurial approaches that address this issue, but there is still a gap between what theory argues and the levels of environmental and social sustainability realized when theory is put into practice. In fact, most research on the topic of sustainable business models is still exploratory and does not fully acknowledge these emerging approaches, whose definitions, boundaries, and defining characteristics are still somewhat vague. This study seeks to contribute to the understanding of the inner entrepreneurial dynamics of innovative sustainable business models. In particular, we focus on the fashion business, a resource-intensive industry in which opportunities to reduce environmental impacts and to innovate business models abound. The aim of our research is to investigate innovative business models in the fashion industry that have sustainability as their defining characteristic, especially in terms of value proposition. In order to do that, we combine a systematic review of the literature with empirical research comprised of six interviews with specialists in sustainability, business model innovation, and the fashion industry, along with eight case studies on innovative fashion startups we define as 'born sustainable.' As a result, we propose a synthesizing framework that discloses trends and drivers of innovative and sustainable business models in the fashion industry. We also highlight opportunities and challenges for researchers and entrepreneurs interested in this topic.
\end{abstract}

KEYWORDS Business model innovation; Sustainable fashion; Born-sustainable startups; Social value creation; Slow fashion; Upcycling

\footnotetext{
* Corresponding author

E-mail addresses: bruna.todeschini@ufrgs.br (B.V. Todeschini), cortimiglia@producao.ufrgs.br (M.N. Cortimiglia), daniela.callegaro@ufrgs.br (D. Callegaro-de-Menezes), antonio1.ghezzi@polimi.it (A. Ghezzi)
} 


\section{Fast fashion: Are there alternatives?}

The fashion industry underwent a remarkable expansion in the last 2 decades, especially with the consolidation of the fast fashion approach, which emphasizes an entrepreneurial modus operandi of rapid acquisition and disposal of massproduced, homogeneous, and standardized fashion items (Fletcher, 2010). However, by stimulating widespread consumption of easily replaceable garments, fast fashion has a significant downside in terms of environmental and social sustainability.

Consumers seem to be aware of these issues, as evidenced by growing interest in green products. As a response, large-scale retailers such as H\&M and Zara have recently invested in sustainable actions and there are reasons to believe this trend will grow. At the same time, cultural and socioeconomic macro-trends such as circular economy and sharing economy are challenging traditional mass production paradigms, driving the need for new and innovative business models that consider sustainability not as an afterthought, but as a crucial design element. Moreover, technological innovation in garment materials and manufacturing processes enable a new way to think about business models that goes beyond scale economies and scope advantages generated by fast fashion. It is a time of opportunity for fashion entrepreneurs to build innovative business models that explore these trends while pursuing not only economic but also social and environmental value creation.

There is still much uncertainty about how innovative and sustainable fashion business models should be structured, as research about the inner dynamics of successful models is still scarce and largely focused on individual cases. No systematic approach that synthesizes the drivers of success for innovative and sustainable business models in the fashion industry has been put forward. That is precisely what we set out to do in this research. First, we identify the large-scale, socioeconomic, and cultural trends that are pressuring the current dominant fast fashion approach. Second, we explore innovative business models in the fashion industry that have sustainability as their defining characteristic, especially in terms of value proposition. By doing so, a number of generic building blocks are identified that describe key working elements (drivers) of such business models. We investigate the interplay between these drivers in eight case studies with innovative and sustainable fashion firms. The final objective is to generalize the findings in a set of challenges and opportunities to innovate and to put forth sustainable business models that could orient academics and entrepreneurs interested in sustainable fashion.

\section{Research strategy}

Although there are studies dealing with sustainable business model innovation (BMI) in the fashion industry (e.g., Beh, Ghobadian, He, Gallear, \& O’Regan, 2016; Kozlowski, Searcy, \& Bardecki, 2015; Lueg, Pedersen, \& Clemmensen, 2015), they usually lack an integrative, holistic perspective. To address this gap, we combined (1) a comprehensive systematic review of literature; (2) interviews with experts in sustainability, BMI, and fashion; and (3) a wide search on the specialized press that covers fashion businesses. As a result, we identified the main trends and drivers of sustainable BMI in the fashion industry. Next, we studied eight fashion startups that illustrate the entrepreneurship implications of the trends and drivers. Finally, we used these cases to frame a discussion of opportunities and challenges for researchers and practitioners interested in this topic.

The first step of the research was a systematic review of the literature (Hallinger, 2013). Sources of data were articles published in academic journals and conference proceedings that included these keywords: business model, innovation, and sustainability (and variants, such as sustainable). These keywords were combined with at least one of the following terms: fashion, garment, or apparel. Three academic databases were searched (Web of Science, Scopus, and Science Direct), resulting in 177 articles. Not every article addressed the issue of interest. Thus, the authors independently evaluated the 177 articles and a restricted sample of the 53 more relevant articles was obtained and subjected to full analysis. In this analysis, concepts that drive sustainability in fashion, as well as examples of innovative business models that make use of these concepts, and direct or indirect mentions of potential challenges and opportunities for sustainable fashion entrepreneurship were identified. Next, the review was complemented with empirical research through interviews with six specialists in the fashion industry and a comprehensive search of news outlets covering the fashion business such as FFW and Fashion Revolution. We also conducted eight case studies with Brazilian and Italian fashion startups. In selecting these cases, we prioritized interesting entrepreneurial stories that illustrate multiple challenges and opportunities and whose inner workings involve multiple drivers. 


\section{Macro-trends shaping the competitive arena for fashion businesses}

We identified five socioeconomic and cultural macro-trends behind the push for sustainable and innovative business model alternatives to the fast fashion paradigm.

\subsection{Consumer awareness}

Among recent changes in consumer habits and preferences, the trend of increased awareness about sustainability is one of the most important elements behind the surge in alternatives to fast fashion. Evidences of such a behavioral change are the increased interest in green products, the proliferation of bottom-up initiatives such as the maker and do-it-yourself movements, the consolidation of exchange and sharing platforms, and the growing notion that younger generations tend to prioritize experiences over ownership. Impacts of this trend in the fashion industry have already been noticed as fast fashion companies have experienced a decrease in sales. These companies have responded with initiatives like H\&M's 2015 partnership with the Ellen MacArthur Foundation to foster the development of circular economy and C\&A's 2014 program to promote circular economy and zero waste. Movements such as lowsumerism and slow fashion are direct expressions of changing consumer preferences about consumption that directly impact how fashion firms design and transform their business models.

\subsection{Circular economy}

The main idea behind the socioeconomic trend of circular economy is to base economic production on purposeful restoration and regeneration. A circular economy is restorative by design and aims to keep products, components, and materials at their highest utility and value at all times. This model strives to decouple economic growth and development from the consumption of finite resources. To do so, it distinguishes between technical and biological materials and focuses on effective design and use of materials to optimize their flow and either maintain or increase technical and natural resource stock. The circular economy provides opportunities for innovation in product design, service, and business models; as a result, it establishes a framework and building blocks for a long-term, resilient system (Webster, 2015). It challenges fast fashion by drawing a sharp distinction between consumption and use of materials, advocating the need for a functional service model characterized by manufacturers or retailers increasingly retaining product ownership and acting as service providers. This paradigm shift has direct implications for the development of efficient and effective take-back systems and the emergence of new design practices that generate more durable products and facilitate disassembly and refurbishment.

\subsection{Corporate social responsibility}

Corporate social responsibility (CSR) aggregates many types of practices at different levels of proactivity, complexity, and time horizons. There is a clear trend toward increased adoption of CSR practices in the fashion industry, including discussions about the ethics of communicating sustainable actions for business purposes and the risk of greenwashing (Baldassarre \& Campo, 2016). In the fashion industry, CSR seems to manifest more often in supply chain management as leading fashion brands have to deal with increasingly complex networks of suppliers that are distributed around the globe. In the fast fashion approach, brands usually outsource production to countries with low-cost labor. The fact that fashion manufacturing is so often dissociated from design, marketing, and consumption and relegated to faraway countries where regulation concerning working conditions is far from stringent has fueled sweatshop-free and fair trade movements that aim to provide fair wages and working conditions in the upstream supply chain. As a result, global fashion brands tend to adopt CSR measures such as sustainability reporting, voluntary participation in multistakeholder monitoring, auditing initiatives such as the Fair Trade Association, development of codes of conduct and labor standards assurance programs, and adoption of supplier disclosure and transparency practices all along the supply chain.

\subsection{Sharing economy and collaborative consumption}

Another defining macro-trend behind sustainable and innovative fashion business models involves the consolidation of sharing economy and collaborative consumption. Among the multiple framings for this phenomenon, we focus on those that consider it a pathway to sustainable consumption and a decentralized, equitable, and sustainable economy. In this perspective, the sharing economy is a global, cultural, and economic paradigm shift from ownership to access manifested in approaches such as collaborative and access-based consumption, 
which can both promote economic growth based on innovation and entrepreneurship and mitigate environmental impacts associated with large-scale production. In this sense, collaborative consumption is not simply a cultural reaction against consumption, but a conscious and efficient alternative for adapting collective and individual needs to available resources. According to Botsman and Rogers (2010), collaborative consumption refers to the expansion and reinvention of exchanging, swapping, bartering, sharing, loaning, and donating practices, usually between people not previously connected.

\subsection{Technological innovation}

Finally, there is a techno-economic trend encompassing various technological innovations, enabling improved sustainability in fashion. Among the technological innovations that currently impact business models in fashion, sustainable or alternative fibers seem to be the most prominent innovations according to our literature review. Impacts include improvements in clothing durability, reduced waste from cleaning processes, and the use of alternative (synthetic) raw materials instead of scarce natural resources. An already mature technology making important inroads in fashion is additive manufacturing, also known as 3-D printing. Finally, short-to-medium term technological trends that have the potential to impact fashion business models include wearable technology and augmented reality. Although still predominantly in the design phase, smart wearables can open up alternatives in terms of monitoring wear and tear of fabrics so as to best detect when and how to discard garments.

\section{Drivers of sustainability-related innovation in fashion business models}

Our literature review uncovered eight drivers of sustainability-related BMI for fashion firms, while the empirical research revealed seven more. The fact that some of the drivers did not appear in the literature reinforces the notion that the shift toward sustainable fashion business models is still emergent and not fully captured by academic literature. These drivers were analyzed according to how they usually impact each of the nine components of a business model, as defined by the business model canvas (Osterwalder \& Pigneur, 2010): value proposition, customer segment, delivery channels, customer relationship, key activities, key resources, value network, cost structure, and revenue streams. Table 1 summarizes the results and aggregates the drivers along with the macrotrends we identified. Next, each driver is briefly described, and the most common impacts in business model canvas parameters are noted.

\subsection{Circular economy}

\subsubsection{Upcycling}

Upcycling refers to the use of wasting materials to generate new goods of equal or higher perceived value, utility, and/or quality than the original products (Dissanayake \& Sinha, 2015). It generates sustainability by reusing resources that would be discarded as raw materials for new products, thus extending their lifespan and decreasing the need for natural resources. In fashion, upcycling has a direct impact on key resources and activities as access to good materials for upcycling can be a source of advantage.

\subsubsection{Recycling}

The recycling driver is based on converting materials from existing products to create different products. As it often involves high-energy processes, it is considered the last choice among the 3 Rs (reduce, reuse, recycle), though it is an important alternative to implementing circular economy principles as it reduces the need for new materials and natural resources consumption. Adopting recycling in a business model implies transformations in the cost structure, key activities, and key partners parameters as firms in the fashion industry tend to acquire recycled materials instead of processing them themselves. A high-profile example of an innovative business model based on recycling is that of Adidas and Parley for the Oceans; the companies developed a sneaker using plastic waste recovered from oceans.

\subsubsection{Vegan}

Vegan refers to an approach to fashion production that deliberately refrains from using raw materials of animal origin. By doing so, it aims to reduce overall energy consumption within the whole system, as extracting and processing animal material tends to require high amounts of energy. The adoption of vegan manufacturing principles potentially impacts four business model parameters: key resources, as it requires specialized resources or suppliers; key partner selection; channels and communication content; and value proposition, as it allows the firm to devise its offering in a way that appeals to consumers who are concerned 
Table 1. Trends and drivers of sustainability-related business model innovation for fashion businesses

\begin{tabular}{|c|c|c|c|}
\hline Macro-trend & $\begin{array}{l}\text { Driver of } \\
\text { sustainable } \\
\text { innovation }\end{array}$ & $\begin{array}{l}\text { Where does it drive innovation in } \\
\text { the business model? }\end{array}$ & $\begin{array}{l}\text { Examples of innovative and } \\
\text { sustainable business models in fashion }\end{array}$ \\
\hline \multirow[t]{3}{*}{$\begin{array}{l}\text { Circular } \\
\text { economy }\end{array}$} & Recycling & $\begin{array}{l}\text { Cost structure, key activities, } \\
\text { key partners }\end{array}$ & $\begin{array}{l}\text { Incumbent: Adidas } \\
\text { Startup: Orange Fiber }\end{array}$ \\
\hline & Vegan & $\begin{array}{l}\text { Key partners, key resources, } \\
\text { channels, value proposition }\end{array}$ & Startup: Preza \\
\hline & Upcycling & $\begin{array}{l}\text { Key resources, key activities, } \\
\text { value proposition }\end{array}$ & Startups: Colibrii, Revoada, Preza \\
\hline \multirow{3}{*}{$\begin{array}{l}\text { Corporate } \\
\text { social } \\
\text { responsibility }\end{array}$} & Sweatshop free & $\begin{array}{l}\text { Customer relationship, key } \\
\text { resources, key activities }\end{array}$ & Incumbent: American Apparel \\
\hline & Fair trade & $\begin{array}{l}\text { Customer relationship, } \\
\text { key partners }\end{array}$ & $\begin{array}{l}\text { Incumbents: People Tree, Eileen Fisher } \\
\text { Startups: Colibrii, Revoada }\end{array}$ \\
\hline & Locally sourced & $\begin{array}{l}\text { Customer relationship, value } \\
\text { proposition, key partners }\end{array}$ & $\begin{array}{l}\text { Startups: Contextura, Lanieri, Orange } \\
\text { Fiber, Revoada, Colibrii }\end{array}$ \\
\hline \multirow{3}{*}{$\begin{array}{l}\text { Sharing economy } \\
\text { and collaborative } \\
\text { consumption }\end{array}$} & Fashion library & $\begin{array}{l}\text { Customer relationship, value } \\
\text { proposition, revenue streams }\end{array}$ & Startups: LENA, Rent the Runway \\
\hline & Second hand & $\begin{array}{l}\text { Value proposition, channels, } \\
\text { customer relationship, key } \\
\text { activities, revenue streams }\end{array}$ & Startup: Armadio Verde \\
\hline & Collaboration & $\begin{array}{l}\text { Key partners, key activities, } \\
\text { key resources, delivery channels, } \\
\text { customer relationship }\end{array}$ & $\begin{array}{l}\text { Startups: Armadio Verde, Preza, } \\
\text { Revoada }\end{array}$ \\
\hline \multirow[t]{3}{*}{$\begin{array}{l}\text { Technological } \\
\text { innovation }\end{array}$} & $\begin{array}{l}\text { Sustainable } \\
\text { raw materials }\end{array}$ & $\begin{array}{l}\text { Key resources, customer } \\
\text { relationship, cost structure }\end{array}$ & Startups: Orange Fiber, Contextura \\
\hline & Zero waste & $\begin{array}{l}\text { Key resources, key activities, } \\
\text { cost structure }\end{array}$ & $\begin{array}{l}\text { Startups: ELSE Corp, Orange Fiber, } \\
\text { Zero Waste Daniel, Contextura }\end{array}$ \\
\hline & Wearables & $\begin{array}{l}\text { Key resources, key activities, } \\
\text { key partners, value proposition, } \\
\text { cost structure }\end{array}$ & Startup: Ringly \\
\hline \multirow[t]{3}{*}{$\begin{array}{l}\text { Consumer } \\
\text { awareness }\end{array}$} & Capsule wardrobe & $\begin{array}{l}\text { Customer relationship, value } \\
\text { proposition, revenue streams }\end{array}$ & \multirow{3}{*}{$\begin{array}{l}\text { Drivers generated mainly by consumer } \\
\text { behavior } \\
\text { Startups: Armadio Verde, Contextura, } \\
\text { Preza, Lanieri }\end{array}$} \\
\hline & Lowsumerism & $\begin{array}{l}\text { Customer relationship, value } \\
\text { proposition, revenue streams }\end{array}$ & \\
\hline & Slow fashion & $\begin{array}{l}\text { Value proposition, customer } \\
\text { relationship }\end{array}$ & \\
\hline
\end{tabular}

with animal rights and/or dedicated to the vegan movement.

\subsection{Corporate social responsibility}

\subsubsection{Sweatshop free}

The concept of sweatshop free involves transparency about working conditions in the manufacturing firm and opposition to the practice of outsourcing production to emerging countries in search of low wage labor. American Apparel is a retailer that promotes vertical integration to generate consumer engagement by increasing consumer awareness about fair treatment. This trend deals with the social aspect of sustainability and impacts the business model parameters of customer relationship, key resources, and key activities.

\subsubsection{Fair trade}

Fair trade aims at offering a worthy wage for all workers involved, as well as healthy workplace environments and social investment for the communities. It addresses the rising awareness about social sustainability among fashion consumers and thus requires the adoption of innovative customer relationship practices. It also impacts the key partners parameter of a business model as it requires fashion brands to rethink and, in many cases, adopt innovative supply chain management procedures for partner selection, monitoring, and rewarding. 
An illustrative example of an innovative business model based on fair trade is People Tree, which sells apparel manufactured by selected companies in emerging countries.

\subsubsection{Locally sourced}

The locally sourced driver consists of prioritizing product manufacturing in regions geographically close to its consumption. How to measure 'closeness' is still debatable and depends on the specific context, but this choice tends to generate sustainability by reducing costs and environmental impact associated with transportation and stimulating local businesses, thus improving employment in local communities. BMI derived from this driver involves how information is communicated to customers and how customers react to it. It impacts customer relationship and value proposition but, more importantly, it influences key partner selection.

\subsection{Sharing economy and collaborative consumption}

\subsubsection{Collaboration}

As a driver of innovative and sustainable business models in fashion, collaboration refers to the adoption of a collaborative mindset by all stakeholders involved in a sustainable value network: suppliers, distributors, customers (who often are involved in co-creating initiatives), and even competitors. In fact, it does not seem uncommon to witness coopetition efforts among sustainable fashion startups. Collaboration allows the creation of a supporting ecosystem that drives resource and knowledge sharing, promotes the diffusion of sustainable practices, and ultimately allows business model experimentation. As a result, it is a critical driver for startups and small businesses and impacts the business model parameters related to value creation (key activities, key resources, and key partners), distribution (delivery channels and customer relationship), and potential impacts on cost structure and revenue streams, as many collaboration initiatives involve revenue sharing.

\subsubsection{Second hand}

Second hand refers to consumers selling or donating apparel no longer in use to other consumers, thus promoting reuse and reducing demand for newly manufactured items and the associated natural resources consumption. This driver is usually associated with items used only a limited number of times, such as baby clothing or party dresses. Impacts on BMI are many, usually in the form of extensive change in value proposition, delivery channels, customer relationship, key activities, and revenue streams.

\subsubsection{Fashion library}

The fashion library (or clothing library) driver is essentially a subscription service for apparel. In this mechanism, the customer does not own the fashion items but can access and use them for a limited time. Examples of successful business models based on this driver are those of Rent the Runway and the Dutch company LENA. By using sharing mechanisms, items that would be used only a few times if owned individually reach a wider audience thus potentially decreasing demand for new apparel. Fashion libraries drive BMI in customer relationship, as it requires a new way to engage customers and cross-upsell to them, and value proposition, which is completely revamped by going from a product-centered to the service logic of consumption. Revenue mechanisms also change from single transactions to usage-based or subscription fees.

\subsection{Technological innovation}

\subsubsection{Sustainable raw materials}

The sustainable raw materials driver contemplates the development and adoption of different types of environmentally-friendly raw materials such as organic cotton, hemp, bamboo, lyocell, and recycled fibers. As a driver of innovation and sustainability in business models, it mainly impacts the key activities, key resources, and customer relationship parameters by requiring technological development, reliable access to a source of materials, and communication of brand commitment to sustainable practices. Impacts on cost structure are not uncommon, as these technologies often have to be internally developed or externally acquired. An innovative business model built upon this driver is Orange Fiber, an Italian startup that creates sustainable fibers using waste from orange juice production.

\subsubsection{Zero waste}

Zero waste is a driver based on the notion of minimizing material waste in apparel production. It generates innovation for sustainability by reducing the use of raw materials through the development and adoption of novel and more efficient production processes, such as additive manufacturing. Adopting zero waste requires innovation in key resources, key activities, and cost structure parameters. Clothing brand Zero Waste Daniel employs a reroll method to achieve a near zero waste production process. 


\subsubsection{Wearable technology}

Wearable technology involves incorporating electronic devices in fashion goods to provide added functionalities, such as health monitoring, or to allow the apparel to change form or appearance. It impacts the value proposition parameter, generating opportunities to create additional value through novelty, improved or expanded functionalities, and exclusivity. It also affects key technologyrelated activities, resources, partners, and costs. Ringly is an example of wearable technology.

\subsection{Consumer awareness}

\subsubsection{Capsule wardrobe and lowsumerism}

The capsule wardrobe and lowsumerism drivers depend fundamentally on the consumer's behavior and attitude. They involve, respectively, a commitment to owning and using only a limited amount of clothes for a fixed period of time (e.g., a season or a year) and the adoption of a generally critical approach to consumption that prioritizes conscious and moderate acquisitions of new goods. These drivers generate sustainability by opposing compulsive consumption and fostering a minimalist conscience among consumers. These drivers require extensive BMI in terms of customer relationship and value proposition, with potential implications also for revenue models.

\subsubsection{Slow fashion}

Slow fashion refers to fashion production and commercialization practices that oppose the fast fashion paradigm. Slow fashion is a social movement akin to the slow food movement that emerged in Italy in response to expanding fast food chains in a country where social and cultural traditions favor regionalized cuisine and a very intimate relationship with food (Fletcher, 2010). Slow fashion drives innovation in value proposition and customer relationship, as firms orient their offering toward increased perceived quality and authenticity and address customer concerns in terms of environmental (by reusing or recycling materials) and social (by prioritizing locally-made products and partners that adopt fair trade principles) impacts.

\section{Fashion startups focused on sustainability}

In order to illustrate the interplay between drivers and their impact on sustainable fashion entrepreneurship, we investigated eight case studies with Brazilian and Italian firms. The role of technology in promoting and exploring these drivers was controlled by selecting an equal number of cases where high technology is either essential or almost absent. We focused exclusively on new businesses, as the literature already covers sustainabilitydriven BMI by incumbents (e.g., Kozlowski et al., 2015). In fact, very little has been discussed about the startups that we label born sustainable, that is, which are originally conceived to develop a new business model leveraging sustainability at its core. Such emerging cases can provide insight into the entrepreneurial dynamics and trends of the sustainable fashion of the future.

\subsection{Preza}

The first case is that of Preza, a Brazilian startup whose original value proposition lies in transforming industrial waste in high-end fashion accessories. Preza's main product is a line of designer sunglasses made of wood waste from the local luxury furniture industry. Its value creation practices are illustrative of the vegan and upcycling drivers, as all raw materials and production inputs are fully environmentally friendly (e.g., solvent-free resins extracted from Brazilian plants). Slow fashion is also a key component of Preza's value proposition: by relying on laborious and time-consuming craft production processes using singular raw materials without any additional painting or finishing, each product is unique and receives an identification number. Preza built a value network of key partners aligned with the same sustainability principles that guide the firm. In fact, collaboration is essential for establishing distribution channels. While the firm manages its own electronic commerce channel, key partnerships with luxury stores provide a distribution network for direct sales. Recently, the firm has explored new venues for revenue creation by promoting a second value proposition targeting corporate clients; instead of wood sunglasses, Preza combined its core competencies in design and technical expertise on treating wood waste to create corporate-branded gifts for large companies wishing to promote or associate themselves with sustainable values.

\subsection{Revoada and Colibrii}

Another Brazilian case is that of Revoada, a fashion startup that illustrates the combined use of drivers such as upcycling, locally sourced, collaboration, and fair trade. Its innovative value proposition involves manufacturing backpacks, wallets, and briefcases using inner tubes of large vehicle tires and discarded umbrellas as substitutes to leather and nylon. Revoada had to create a supplier network from scratch, as these items were not sorted 
out in Brazilian recycling centers. Fair trade is promoted by paying for this material the prices equivalent to the most expensive materials sold by the recycling centers. As suppliers do not have sustainability as a core value, adopting fair trade is a way to assure supplier commitment. The business model was innovated three times in the 4 years of Revoada's existence. Initially, individual consumers were targeted directly (e-commerce) and indirectly (collaboration with alternative fashion stores). The high upfront costs of building inventory and low engagement of partner stores in promoting the sustainable value of the products led to the first change in the business model, which pivoted toward business-to-business. This second value proposition was based on manufacturing green products to corporate customers wishing to associate their brands with sustainability. The success of this model stretched Revoada's production capacity but promoted much-needed growth. Today, the firm is experimenting again. It successfully tested a crowdfunding model for direct e-commerce sales, restricting production to a minimum order size and a consulting model for corporate clients. The corporate-client value proposition involves providing services based on the firm's expertise with design and green product development for firms who want to create their own innovative and sustainable initiatives. The business model of Colibrii, the third Brazilian case, is similar to that of Revoada, as it employs upcycling by handcrafting backpacks and purses using textile industry waste as raw material. Production is outsourced to local artisans, an example of how locally sourced and fair trade drivers appear in low-tech fashion startups.

\subsection{Contextura}

Contextura is the fourth Brazilian case, and its business model combines the slow fashion and zero waste drivers. Garments are handcrafted from reused textiles and alternative sustainable materials (i.e., recycled PET, sustainable fibers). Drawing from the locally sourced driver, production is outsourced to local artisans, which limits scalability and growth. Following lowsumerism principles, products are designed to be timeless and versatile, so garments can be used in many different ways and situations. The company employs a direct sales model, combining an e-commerce platform with a locally-owned retail store and partner retail stores all over Brazil.

\subsection{Armadio Verde}

Four Italian case studies were also conducted. These startups focus on technology to enable the drivers of sustainable innovation. Armadio Verde is an online platform for children's clothing exchange that draws from the lowsumerism, second hand, and collaboration drivers. The startup created a point-based exchange mechanism for donating and acquiring second-hand garments for newborns and children up to 16 years old. By donating used clothes, members can obtain credits to spend on other clothes made available through the platform, thus triggering engagement and collaboration. Armadio Verde fosters a new fashion experience, based on values such as high quality (all garments are controlled for quality and brand upon their receipt), sustainability, innovation, and sharing, saving both money, time, and resources. By focusing on children, the startup also has strong potential for promoting customer education.

\subsection{Orange Fiber}

Orange Fiber is a startup aiming to create sustainable textiles from citrus juice byproducts. In Italy alone, more than 1 million tons of citrus byproducts are wasted every year. Orange Fiber came up with the original and inherently sustainable idea to reuse this waste (like orange, lemon, and grapefruit peels) by transforming them into cellulose fibers, thus developing an innovative fabric to be used later for manufacturing clothes. To do so, the startup designed, developed, and patented a process based on nanotechnology that replaces highly polluting raw materials with natural elements. The resulting sustainable textile represents a brand new opportunity for Italian tradition in high-quality textiles and fashion. The Orange Fiber business model leverages and resembles the sustainability drivers of sustainable raw materials, recycling, local sourcing, and zero waste.

\subsection{Lanieri}

Lanieri is the first e-commerce platform to propose entirely made-in-Italy, made-to-measure men's clothing online, drawing from the slow fashion and locally sourced drivers. In its platform, the customer may choose among various Italian fabrics, customize the model (choices for buttons, linings, collars, pockets, waistbands, and cuffs allow more than 10 million combinations) and provide their measurements thanks to a 3-D configurator. Lanieri also provides expert tailors in many European cities for face-to-face interaction, an option that explores locally sourced dynamics. 


\subsection{ELSE Corp}

Finally, ELSE Corp combines 3-D product configurator and hybrid manufacturing technologies in a mass customization platform that recently incorporated augmented reality features. Its main value proposition lies in providing third parties with smart mirror and dressing room technology that can minimize store inventory, thus enabling virtual or no stock retail for the apparel and footwear industry while capitalizing on the zero waste driver.

\section{What entrepreneurial challenges and opportunities lie ahead?}

There are a number of entrepreneurial challenges and opportunities identified in our analysis. Challenges are issues that repeatedly appear as critical barriers to the success of the reviewed business models. As such, they represent issues that must be solved in order to fully enable a paradigmatic shift toward innovation and sustainability in fashion. On the other hand, opportunities are elements that have already been technically or economically incorporated in viable-and, in some cases, successfulbusiness models, but require additional development, exploitation, expansion, or diffusion.

\subsection{Challenges}

\subsubsection{Design phase strategy}

An key challenge is to rethink the design phase of sustainable product development. Decisions affecting the whole product are made during the design phase concerning quality, appearance, materials, manufacturing processes, and associated costs. As such, design decisions impact the whole business model but have particularly critical influence on the translation of sustainability principles to the value proposition. In this sense, adoption of environmentally-friendly materials (e.g., sustainable fibers or recycled materials) and production processes (e.g., natural dyeing techniques, zero waste mechanisms, slow fashion methods) can yield relevant business benefits. However, the decision to adopt such materials still represents a challenge for fashion firms that still do not perceive it as a strategic priority for the industry. Moreover, the design phase is fraught with technical challenges. Dissanayake and Sinha (2015) pointed out that concept development for goods making use of postconsumer waste is severely limited by dimensions, types, colors, and shapes of available material stock, which often has to be disassembled manually in a time-consuming process. In addition, design decisions must take into account the availability of recycled materials in order to maximize repeatability. As a result, the design phase of apparel that makes use of recycled materials ends up being completely different from the design phase of traditional fashion items, usually requiring a "high level of design thinking and creativity" (Dissanayake \& Sinha, 2015, p. 98). Born-sustainable startups Preza and Revoada tackled this issue by creating strong relationships with suppliers that provide somewhat standardized raw materials, while Orange Fiber redesigned the whole textile development process through patented technologies. The owners of Contextura are academic researchers on redesigned sustainable materials and processes, and their applied research is often tested in the firm.

\subsubsection{Consumer education}

Another potential cause of failure of many of the reviewed sustainable business models is related to consumer education. On the one hand, many sustainable and innovative business models have failed to convince consumers about the benefits of sustainable fashion products. For instance, empirical research has suggested that most of the defining dimensions of slow fashion are simply not recognized as valuable by their consumers. Consumer education about such potential benefits can be a first step in the direction of viable business models based on this approach. On the other hand, consumer education can be a catalyst for changes in consumer behavior toward more sustainable individual practices related to fashion. A key component of this challenge is to convince consumers that it is worthwhile to dedicate efforts toward increasing the value of existing garments by expanding their lifespan and creatively finding new uses for them (Wang \& Song, 2010). In this sense, traditional approaches to laundry must be rethought, since this is one of the most energy-intensive processes in a garment's life. Thus, consumers could be educated on cleaning methods that not only demand less energy but also increase clothes' durability such as natural drying and hand washing instead of machine washing (Wang \& Song, 2010).

Consumers could be oriented toward more sustainable consumption behaviors in order to decrease consumption levels, making better use of collaborative consumption solutions such as fashion libraries and rewarding upcycling and recycling initiatives. All of the cases show how critical this challenge is, which manifests in low demand for green products. Preza and Revoada innovated their business models in response to this challenge, adding a new value proposition aimed at corporate customers; Armadio Verde leveraged an online plat- 
form to foster collaboration and engagement between members, and explicitly targeted children (the consumers of the future) so as to educate them about consumption of resources as well as sharing opportunities.

\subsubsection{Consumer expectations}

A challenge closely related to consumer education involves addressing consumers' sustainability expectations. Consumer education is necessary to expand the awareness about sustainability, which is still rather limited, to large crowds of consumers. Paradoxically, however, excessive expectations within the small niche of consumers already oriented toward sustainability in fashion may be a problem. For traditional businesses strongly associated with fast fashion, it may be difficult to promote enough change toward sustainability as to effectively shift perceived brand image. Certifications are a first step in this direction, but more is needed to significantly change consumers' perceptions about the actions and intentions of firms toward sustainability (Ansett, 2007). Fast fashion firms tend to adopt defensive sustainability strategies due to risks associated with offer cannibalization and lowered performance, while born-sustainable startups are created following values and principles of sustainability and tend to adopt a much more proactive strategy, incorporating innovation and working in supply chain models built upon collaboration and innovation.

\subsubsection{Aligning values along the supply chain} Next, it is necessary to improve solutions for aligning values along supply networks, thus creating truly collaborative arrangements and building stakeholder commitment in sharing knowledge, resources, and abilities. The search for sustainability within fashion supply chains involves recommercialization, for instance by selling products from past collections or second-hand items (as Armadio Verde does). In the first case, participants in the value network are required to set up a reverse supply chain, that is, to move the product backward from consumer to manufacturer, and redirect the product to a new sales channel, usually in the form of outlets. For second-hand items, different value network actors are involved, because a new consumer segment is targeted. In both cases, however, beyond nurturing technical competencies associated with logistics and commercialization, partners in the value network are required to exchange knowledge about consumers, marketing strategies, and channel operation. Advantages arising from sharing competencies and knowledge can include a significant reduction in associated costs and improved market performance (Beh et al., 2016), but the operationalization of complex collaborative efforts involving more than knowledge sharing is a significant challenge for participating firms, as attested by the example of Revoada's supply chain orchestration. Not only are there technical issues to be solved (e.g., integrating logistics and information systems, setting up rules for exchanging knowledge, establishing collaborative marketing strategies in different regional contexts), but misaligned organizational values can derail efforts to effectively engage in strategic partnerships. The challenge of aligning values along the supply chain extends to clients. In the Preza case, the partners reported an interesting potential dilemma: Would they accept orders from a corporate customer whose public image was unmistakably linked to industries with high environmental impacts?

\subsection{Opportunities}

We also identified a number of entrepreneurial opportunities that may be acted upon to expand the reach and success of sustainability-based innovative fashion business models.

\subsubsection{Enhanced focus on CSR}

A first opportunity is to enhance the focus on CSR. Consumer perception of CSR actions is constantly improving, to the point that CSR is starting to be a factor of influence when it comes down to purchase decisions. The importance of communicating CSR practices stands out as a significant opportunity for expansion and improvement (Lueg et al., 2015). Contextura partners with a social organization that develops entrepreneurship opportunities in socially vulnerable communities, hiring women (mostly mothers without other sources of income) as artisans to work at home. In this context, it builds upon the sweatshop free, fair trade, and locally sourced drivers. It is also worth noticing the expansion of CSR efforts as an opportunity to address a challenge we mentioned above: that of consumer education about the benefits of sustainable fashion. The cases of Armadio Verde, Lanieri, Preza, and Revoada illustrate how this opportunity is being explored by born-sustainable fashion startups. On the one hand, green products can be customized and sold to corporate customers, who often use it to promote their commitment to sustainability. On the other hand, startups can use their expertise in sustainable innovation to provide consulting services, knowledge, and networking to large firms wishing to further their CSR commitment by developing their own green products and initiatives. 


\subsubsection{Service-based business models}

The latter is also an example of the second opportunity we identified: the development of service-based business models that reduce stock requirements (like in the Lanieri and ELSE Corp cases) or even forego production entirely. Other than consulting, this includes mechanisms such as fashion libraries or garment subscription schemes. Services were always present in the fashion industry, but the scale of fast fashion firms seems to have diminished interest in service-based business models. The idea is to migrate from the acquisition of new fashion goods toward the reinvention and restyling of existing goods. After-sale services are suggested by Wang and Song (2010) in order to help customers to maintain (hand washing instead of machine washing, drying naturally) and recycle garments.

\subsubsection{Monetizing voluntary simplicity}

A final opportunity involves monetizing the voluntary simplicity embedded in drivers of sustainable innovation such as upcycling and second hand, which are central to many of the successful business models reviewed in this article. In the fast fashion model, consumers are usually distant from production processes. This distance implies less emotional appeal in the acquisition and use of fashion goods that is necessary for large-scale immoderate consumption. Voluntary simplicity focuses on the careful use of apparel and an appeal for broader usefulness in order to decrease the production of fashion goods and the associated consumption of natural resources (Ruppert-Stroescu, LeHew, Connell, \& Armstrong, 2015). In the reviewed business models, voluntary simplicity occurs with upcycling and second hand, which have already been proven viable in small-scale initiatives but are yet to be incorporated into scalable business models. The case of Contextura is a typical example of fashion startup that explores this opportunity with little technology investments, as their products are purposely designed as classic, timeless, and versatile; meanwhile, Armadio Verde shows how technology can be leveraged to set up a platform to simplify and foster the exchange of second-hand garments.

\section{Implications for fashion entrepreneurship}

Although our study is exploratory, it puts forward a number of implications for fashion entrepreneurs. A first general implication is that sustainabilityoriented $\mathrm{BMI}$ in fashion tends to be markedly different for incumbents and startups. A similar result had previously been reported by Cortimiglia, Ghezzi, and Frank (2016), but for a general context; evidence that this dynamic is replicated in a very specific setting is an important contribution to the literature on BMI. Indeed, fashion startups are typically born sustainable, as commitment to promoting social and environmental sustainability tend to be key values and motivations of founders and partners. As a result, these entrepreneurs leveraged the startups' flexible state to design innovative business models that deliberately embed many of the trends and drivers we pinpoint in this study. Incumbents, however, are characterized by resource rigidity and strong legacy with the established fast fashion paradigm; therefore, they tend to proceed cautiously, experimenting with small-scale green initiatives and addressing structural issues such as promoting transparency in supplier selection and management.

A second general implication refers to the role of technology in enabling sustainable BMI for fashion startups. It seems that high technology is helpful when it comes to radically rethinking manufacturing processes (as Orange Fiber did), but is not a hard requirement for successful innovative fashion business models. In fact, smallscale initiatives using limited technology can be an important launching pad for experimentation. When a viable model is found, however, technology can be useful to scale up the business. Preza is illustrative of this dynamic. After a slow start building technical competencies and proving product viability, investments in technology allowed it to increase production capacity to match the controlled growth of the distribution network of partners and, consequently, demand.

A third implication from the cases is that sustainability drivers are seldom exploited alone by born-sustainable startups. Consistently with entrepreneurship literature, startups create their unique value proposition by originally recombining different approaches, resources, and competencies with synergic effects (as in Orange Fiber's combined use of sustainable raw materials, recycling, local sourcing, and zero waste or Colibrii's leverage on locally sourced components, upcycling, and fair trade). The resulting new business model proves capable of both generating and capturing value.

Specific findings from the case studies are also insightful. First, several cases highlighted the importance of partner commitment and engagement. This leads to at least two relevant strategic issues: how to align values and interests along a typically complex value network and how to promote the sustainability aspects of the value proposition (and, indirectly, promote consumer education) when 
partnering with indirect sales channels. The cases also suggest typical challenges for scaling up fashion startups. Among these challenges, a common theme is that of keeping true to the core sustainability values, which are strongly tied to essential drivers such as fair trade, commitment to recycling, upcycling, and use of sustainable materials. A third insight refers to the critical importance of a supporting business ecosystem of like-minded firms that share sustainability values. Shared values promote knowledge and resource sharing and facilitate the establishment of collaborative efforts that foster business model experimentation, especially at the startup stage. This finding leads to another major challenge in the development of a sustainable fashion industry: closing the gap between incumbent fashion companies willing to innovate their business model toward sustainability and born-sustainable startups striving to make their business model replicable and scalable. Incumbents are relatively effective in establishing competitive advantages but less able to identify new opportunities and change accordingly, while startups are inherently more innovative but less successful in developing competitive advantages needed to appropriate value from those innovations. Thus, strategic collaborations between these players within an open innovation framework would be beneficial to the industry as a whole.

To summarize, this study has addressed the pressing issue of sustainability in the fashion industry by identifying the entrepreneurial drivers, challenges, and opportunities to pursue sustainable BMI. It also depicted how such phenomena impact fashion companies' business models. The study's limitations refer to possible sample selection bias in the cases analyzed and observer bias of interview-based qualitative research. Future research should disentangle how to tackle the challenges and to take advantage of opportunities for sustainable evolution of fashion business models, driven by enlightened incumbents and born-sustainable startups.

\section{References}

Ansett, S. (2007). Mind the Gap: A journey to sustainable supply chains. Employee Responsibilities and Rights Journal, 19(4), 295-303.

Baldassarre, F., \& Campo, R. (2016). Sustainability as a marketing tool: To be or to appear to be? Business Horizons, 59(4), 421-429.

Beh, L., Ghobadian, A., He, Q., Gallear, D., \& O’Regan, N. (2016). Second-life retailing: A reverse supply chain perspective. Supply Chain Management, 21(2), 259-272. Botsman, R.,

\& Rogers, R. (2010). What's mine is yours: The rise of collaborative consumption. New York: HarperCollins.

Cortimiglia, M., Ghezzi, A., \& Frank, A. (2016). Business model innovation and strategy making nexus: Evidence from a crossindustry mixed-methods study. R\&D Management, 46(3), 414-432.

Dissanayake, G., \& Sinha, P. (2015). An examination of the product development process for fashion remanufacturing. Resources, Conservation, and Recycling, 104(Part A), 94-102.

Fletcher, K. (2010). Slow fashion: An invitation for systems change. The Journal of Design, Creative Process, and the Fashion Industry, 2(2), 259-265.

Hallinger, P. (2013). A conceptual framework for systematic reviews of research in educational leadership and management. Journal of Educational Administration, 51(2), 126-149.

Kozlowski, A., Searcy, C., \& Bardecki, M. (2015). Corporate sustainability reporting in the apparel industry: An analysis of indicators disclosed. International Journal of Productivity and Performance Management, 64(3), 377-397.

Lueg, R., Pedersen, M., \& Clemmensen, S. (2015). The role of corporate sustainability in a low-cost business model-A case study in the Scandinavian fashion industry. Business Strategy and the Environment, 24(5), 344-359.

Osterwalder, A. , \& Pigneur, Y. (2010). Business model generation: $A$ handbook for visionaries, game changers, and challengers.

New York: John Wiley \& Sons.

Ruppert-Stroescu, M., LeHew, M., Connell, K., \& Armstrong, C. (2015). Creativity and sustainable fashion apparel consumption-The fashion detox. Clothing and Textiles Research Journal, 33(3), 167-182.

Wang, J., \& Song, J. (2010). The strategy investigation of the garment industry based on low-carbon economy situation. In J. K. Hung, Z. Huanchun, \& W. Zongjie (Eds.), Proceedings of the 2010 International Symposium on Low-Carbon Economy and Technology Science (pp. 92-95). Melbourne, FL: St PlumBlossom Press.

Webster, K. (2015). Thecirculareconomy:Awealthofflows. Cowes, UK: Ellen MacArthur Foundation Publishing. 